\title{
PERFORMANCE OF EVACUATED TUBE SOLAR COLLECTOR USING WATER-BASED TITANIUM OXIDE NANOFLUID
}

\author{
M. Mahendran ${ }^{1}$, G.C. Lee ${ }^{1}$, K.V. Sharma ${ }^{2}$, A. Shahrani ${ }^{1}$ and R.A. Bakar ${ }^{1}$ \\ ${ }^{1}$ Faculty of Mechanical Engineering \\ Universiti Malaysia Pahang, 26600 Pekan, Pahang, Malaysia \\ Email: mahen_mu@yahoo.com \\ ${ }^{2}$ Jawaharlal Nehru Technological University Hyderabad, Kukatpally, \\ Hyderabad 500 085, Andhra Pradesh, India
}

\begin{abstract}
Experiments are undertaken to determine the efficiency of an evacuated tube solar collector using water-based Titanium Oxide $\left(\mathrm{TiO}_{2}\right)$ nanofluid at the Pekan Campus $\left(3^{\circ} 32^{\prime} \mathrm{N}, 103^{\circ} 25^{\prime} \mathrm{E}\right)$, Faculty of Mechanical Engineering, University Malaysia Pahang, for the conversion of solar thermal energy. Malaysia lies in the equatorial zone with an average daily solar insolation of more than $900 \mathrm{~W} / \mathrm{m}^{2}$, which can reach a maximum of $1200 \mathrm{~W} / \mathrm{m}^{2}$ for most of the year. Traditionally water is pumped through the collector at an optimum flow rate, for the extraction of solar thermal energy. If the outlet temperature of the water is high, further circulation of the water through the collector is useless. This is due to the low thermal conductivity of water of $0.6 \mathrm{~W} / \mathrm{m} . \mathrm{K}$ compared to metals which is many orders higher. Hence it is necessary to reduce the surface temperature either by pumping water at a higher flow rate or by enhancing the fluid's properties by the dispersion of nanoparticles. Pumping water at higher flow rates is not advantageous as the overall efficiency of the system is lowered. Liquids in which nanosized particles of metal or their oxides are dispersed in a base liquid such as water are known as 'Nanofluids'. This results in higher values of thermal conductivity compared to the base liquid. The thermal conductivity increases with the concentration and temperature of the nanofluid. The increase in thermal conductivity with temperature is advantageous for application in collectors as the solar insolation varies throughout the day, with a minimum in the morning reaching a maximum at 2.00p.m and reducing thereafter. The efficiency of the collector estimated using a $\mathrm{TiO}_{2}$ nanofluid of $0.3 \%$ concentration is about 0.73 , compared to water which is about 0.58 . The efficiency is enhanced by $16.7 \%$ maximum with $30-50 \mathrm{~nm}$ sized $\mathrm{TiO}_{2}$ nanoparticles dispersed in the water, compared to the system working solely with water. The flow rate is fixed at 2.7 liters per minute for both liquids.
\end{abstract}

Keywords: Solar Energy, Nanofluid, Evacuated Tube Solar Collector

\section{INTRODUCTION}

The solar radiation intensity in Malaysia varies due to the high humidity and unpredictable weather, especially during the monsoon period. It was observed (Othman, Sopian, Yatim, \& Dalimin, 1993) that the instantaneous solar radiation intensity or insolation can reach as high as $1400 \mathrm{~W} / \mathrm{m}^{2}$ in Malaysia. Many parts of Malaysia have a short duration of sunshine hours. Hence an efficient solar collector system for Malaysian conditions should be designed in order to absorb the maximum heat with minimum convective loss. Many researchers have concluded that systems employing an 
evacuated tube solar collector (ETSC) have higher efficiencies compared to a conventional flat plate collector (FPC) (Badar, Buchholz, \& Ziegler, 2011; Gordon \& Society, 2001; Morrison, Budihardjo, \& Behnia, 2005). The features of an ETSC are an assembly of rows of concentric glass tubes, placed in parallel to each other, with a vacuum between the tubes. The tubes are transparent to solar radiation for a wide range of wavelengths. The outer surface of the inner tube is coated with a certain material, to absorb the maximum solar radiation. The fluid flows in the inner tube absorbing thermal energy. The method of energy transfer can be direct or indirect, depending on the design. In the indirect method, a secondary fluid transfers the heat to the working fluid with the aid of a heat exchanger. The secondary fluid can be water, liquid refrigerant or a nanofluid (Gordon \& Society, 2001).

Nanofluids are an engineered preparation of fluids created by dispersing nanosized metal or metal oxide particles in a base liquid such as water. The nanofluids are observed (Choi \& Eastman, 1995; Srinivasa Rao, Sharma, Chary, Bakar, Rahman, Kadirgama, \& Noor, 2011; Syam Sundar \& Sharma, 2011a,b) to possess higher thermal conductivity. Hence higher heat transfer coefficients are obtained due to the enhanced thermal properties compared to base liquid. Lee, Choi, Li, \& Eastman (1999) found that the enhancement of thermal conductivity in the range 7-30\% when aluminum oxide $\left(\mathrm{Al}_{2} \mathrm{O}_{3}\right)$ and copper oxide $(\mathrm{CuO})$ nanoparticles were suspended in water and ethylene glycol in a 1-5\% particle volume fraction. Experiments were undertaken by Pak and Cho (1998) for the determination of forced convection heat transfer coefficients with 13 $\mathrm{nm} \mathrm{Al}_{2} \mathrm{O}_{3}$ and $27 \mathrm{~nm} \mathrm{TiO}_{2}$ submicron particles dispersed in water. They observed that heat transfer coefficients increased with concentration. In recent studies, the thermal conductivity enhancement of base liquids using carbon nanotube (CNT) based nanofluids were tested in solar collectors by Natarajan and Sathish (2009). The efficiency of the conventional solar water was reported to increase when these fluids are used as a heat transport medium. The effect of nanofluids on a micro solar thermal collector was studied by Otanicar, Phelan, Prasher, Rosengarten \& Taylor (2010). The solar thermal collectors improved by up to a 5\% efficiency when using nanofluids as the working fluid. Yousefi, Veysi, Shojaeizadeh \& Zinadini (2012) compared the efficiency of a FPC using water-based alumina nanofluids with and without Triton X-100 as the surfactant. The results showed that alumina nanofluids using the surfactant improved the heat transfer of the system and enhanced the efficiency by up to $15.63 \%$. The present paper's objective is to study the efficiency of ETSC using water-based $\mathrm{TiO}_{2}$ nanofluid as the working fluid compared to a base fluid. Hence to predict the efficiency of ETSC using water-based $\mathrm{Al}_{2} \mathrm{O}_{3}$ with experimental data.

\section{EXPERIMENTAL SETUP}

A schematic diagram of the experimental system is shown in Figure 1, and the actual photograph of the experimental system is shown in Figure 2. The experimental apparatus of the solar system mainly consists of a 16-tube ETSC module, a digital flow rate meter, a thermocouple monitor, an air-cooled heat exchanger, an electrical water pump, a solar meter and a power supply. The specifications of the ETSC used in this experiment are given in Table 1. The digital flowmeter offered two decimal reading values ranging from 1.00 to 10.00 liters per minute (LPM). The solar collector was tilted at an optimum angle of $8.2^{\circ}$ facing due south, based on the method suggested by Nayak (2008). Global solar radiation was measured with a portable solar meter, an ranged from 0 to $1200 \mathrm{~W} / \mathrm{m}^{2}$. The inlet and outlet temperatures of the fluid entering and 
leaving the solar collector and the surrounding ambient temperature are monitored on 3 channels with a thermocouple monitor. An air-cooled heat exchanger was used to dissipate the heat from the hot fluids leaving the collector. The electrical water pump with $0.5 \mathrm{Hp}$ has a maximum flow rate of about 14.0 LPM, as shown in Figure 1. The storage tank has a capacity of 8.0 liters and is connected to an electrical pump. The fluid is pumped through the system at an optimum flow rate of 2.5 LPM for the distilled water and remained constant throughout the experiment. Experiments are undertaken at flow rates of 2.0, 2.7, 3.0 and 3.5 LPM. From the graph drawn between the temperature differences versus insolation for various flow rates, it is observed that a flow rate of 2.5 LPM gives the maximum temperature difference. The cooled return fluid from the solar collector and bypass valve are connected to the storage tank. The system is a closed loop as shown in Figure 1. The fluid mass flow rate was controlled using a flow-control valve, in which the bypass valve was normally kept open.

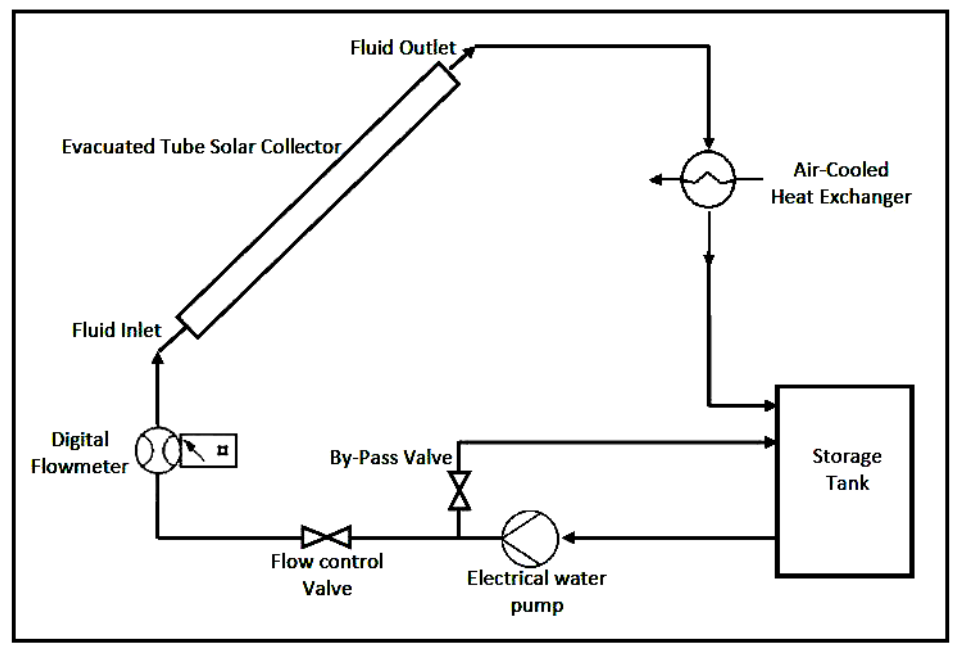

Figure 1. Schematic diagram of the experimental system.

Table 1. Specification of evacuated tube solar collector.

\begin{tabular}{lll}
\hline Specification & Dimension / Material & Unit \\
\hline Length x Width x Height & $2126 \times 1920 \times 150$ & $\mathrm{~mm}$ \\
Absorber area & 2.77 & $\mathrm{~m}^{2}$ \\
Gross area & 4.08 & $\mathrm{~m}^{2}$ \\
Weight & 100 & $\mathrm{~kg}$ \\
Glass material & Borosilicate glass & - \\
Glass tube diameter & 100 & $\mathrm{~mm}$ \\
Wall thickness & 2.5 & $\mathrm{~mm}$ \\
Transmittance & $>0.90$ & - \\
Absorptance & $>0.92$ & - \\
Emittance & $<0.08$ & - \\
Absorber material & Aluminum & - \\
Selective coating & Aluminum Nitride & - \\
Header box material & Aluminum & - \\
Header box size & $1918 \times 108 \times 126$ & $\mathrm{~mm}$ \\
Pressure drop per module & $<20$ & $\mathrm{mbar}$ \\
\hline
\end{tabular}


All the measuring instruments were calibrated before the experiment was conducted. The digital flow rate was calibrated with the aid of a measuring jar. The test was repeated several times to ensure that the readings are within the acceptable range of less than $1 \%$ variation. The thermocouple monitor temperatures reading are checked and compared with a portable thermocouple device which has a valid calibrated certificate to verify that the readings are equivalent.

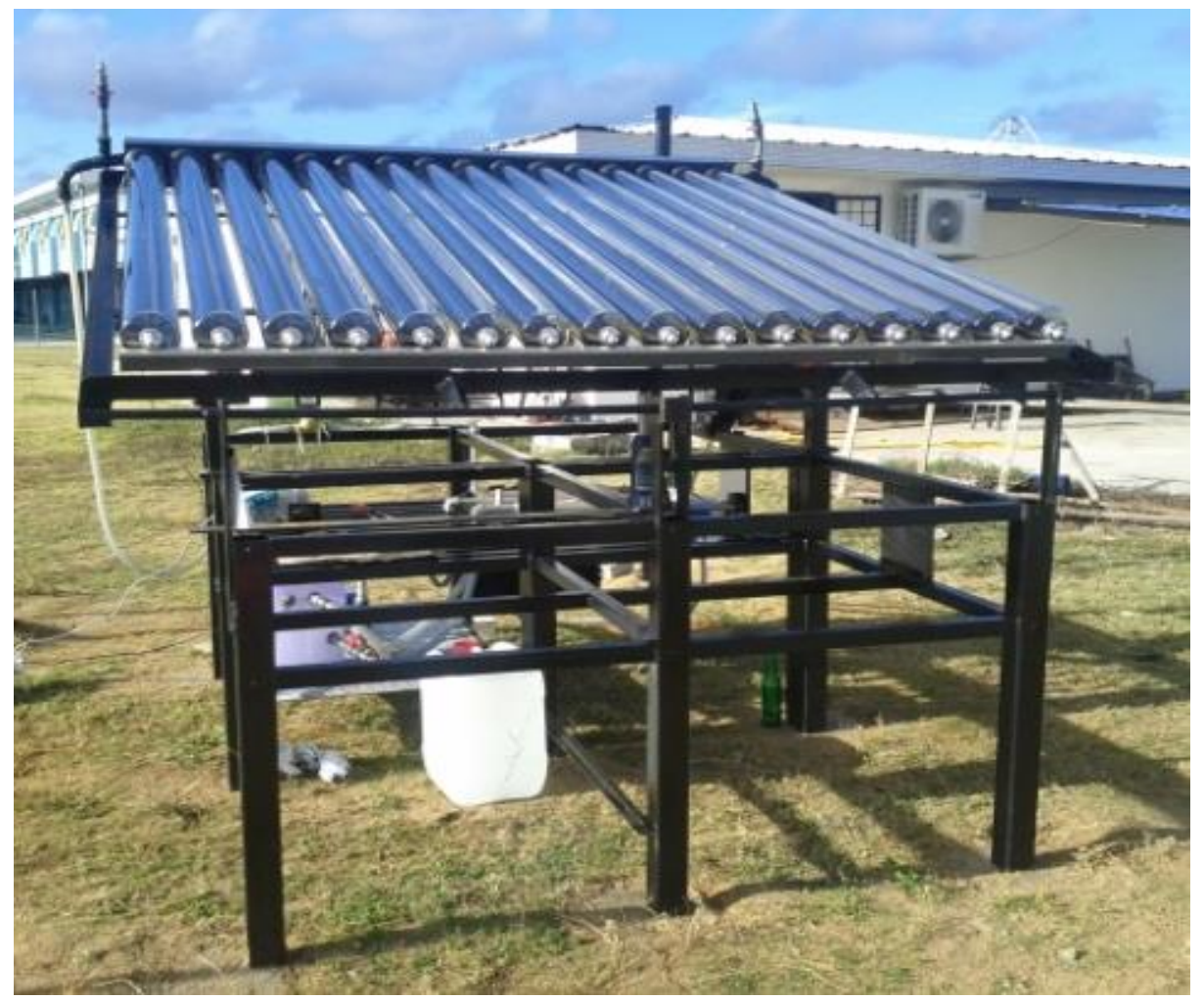

Figure 2. Actual photograph of the experimental system.

\section{Material}

A commercial $\mathrm{TiO}_{2}$ nanopowder dispersion of 40 weight percent was used in this experiment. It has a $99.5 \%$ purity and an average particle size $30-50 \mathrm{~nm}$. Nanoparticle dispersions are suspensions of nanoparticles in water. The $\mathrm{TiO}_{2}$ nanopowder dispersion diluted with distilled water was used during the study as the base fluid. The physical properties of the nanoparticles used in the present experiment and the analysis are given in Table 2.

Table 2. Physical properties of nanomaterials.

\begin{tabular}{ccccc}
\hline Nanoparticle & $\begin{array}{c}\text { Thermal } \\
\text { conductivity, W/m.K }\end{array}$ & $\begin{array}{c}\text { Density, } \\
\mathrm{kg} / \mathrm{m}^{3}\end{array}$ & $\begin{array}{c}\text { Specific heat, } \\
\mathrm{J} / \mathrm{kg} . \mathrm{K}\end{array}$ & References \\
\hline $\mathrm{TiO}_{2}$ & 8.4 & 4175 & 692 & Pak \& Cho (1998) \\
$\mathrm{Al}_{2} \mathrm{O}_{3}$ & 36 & 3880 & 773 & Pak \& Cho (1998) \\
\end{tabular}




\section{Preparation of Nanofluid}

The two-step method was used to disperse the $\mathrm{TiO}_{2}$ nanopowder into the distilled water. The two-step method is an enhanced method for the preparation of metal or metal oxide nanofluids. It has the advantage of reduced agglomeration (Das, Choi, Yu, \& Pradeep, 2007; Hwang, Ahn, Shin, Lee, Kim, Park, \& Lee, 2006; Zhu, Lin, \& Yin, 2004). A measured quantity of $\mathrm{TiO}_{2}$ nanopowder is dispersed in distilled water, to obtain a $0.3 \%$ volume percent $\varphi$ nanofluid. The nanofluids are dispersed with the aid of a mechanical stirrer, shown in Figure 3, for about 2 hours to achieve a homogenously dispersed solution.

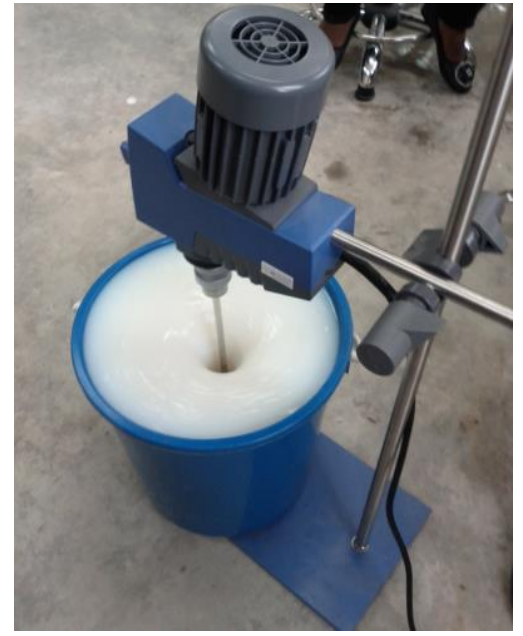

(a) Stirred $\mathrm{TiO}_{2}$ nanofluid

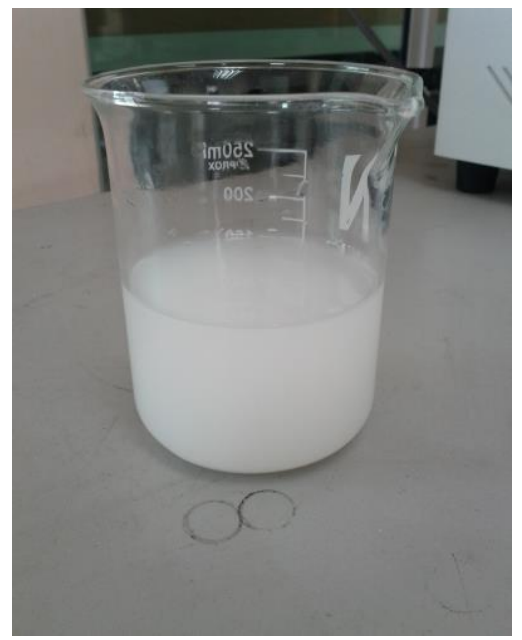

(b) Prepared $\mathrm{TiO}_{2}$ nanofluid

Figure 3. Titanium oxide nanofluid preparation

The concentration in weight percentage, ${ }^{\omega}$, is converted into a volume percentage, $\varphi$, with Eq. (1), using the nanoparticle density listed in Table 2 . The volume of distilled water to be added $\Delta V$ for attaining a desired concentration $\varphi_{2}$ can be estimated with Eq. (2) with the initial conditions of $V_{l}$ and $\varphi_{l}$.

$$
\begin{gathered}
\varphi=\frac{\omega \rho_{w}}{\left(1-\frac{\omega}{100}\right) \rho_{p}+\frac{\omega}{100} \rho_{w}} \text { where } \omega=\left[m_{p} /\left(m_{p}+m_{w}\right)\right] \times 100 \\
\Delta V=\left(V_{2}-V_{1}\right)=V_{1}\left(\frac{\varphi_{1}}{\varphi_{2}}-1\right)
\end{gathered}
$$

\section{Determination of Specific Heat Capacity of Nanofluid}

Zhou, Wang, Peng, Du, and Yang (2010) compared the specific heat capacity of $\mathrm{CuO}$ or ethylene glycol (EG) nanofluid at different volume concentrations obtained through experiments with Eq. (3). The experimental values decreased from 2550 to $2450 \mathrm{~J} / \mathrm{kg} . \mathrm{K}$ with an increase in volume concentration from 0.1 to $0.6 \%$. The experimental values are 
higher than the values calculated with Eq. (3), developed according to the law of mixtures.

$$
C_{n f}=\frac{(1-\phi)(\rho C)_{w}+\phi(\rho C)_{p}}{(1-\phi) \rho_{w}+\phi \rho_{p}}
$$

\section{Collector Thermal Performance Testing Method}

The thermal performance of the ETSC was tested according to the ASHRAE / ANSI Standard 93-2003. This standard can also be used to determine the thermal performance of a FPC and concentrating solar collector (CSC). The instantaneous efficiency at different combinations of solar insolation, ambient temperature, and fluid inlet temperature are obtained to determine the thermal performance of the collector. The test data were measured when the system was maintained for a period of 15 minutes at a steady-state or quasi-steady state condition, as a permitted deviation in measured parameters during a period as listed in Table 3. After a steady-state or quasi-steady state condition was maintained, the data were measured at intervals of 15 minutes from 9.00 a.m. until 6.00 p.m. Invalid data which is not at steady-state or quasi-steady state conditions were ignored.

Table 3. Permitted deviations of measured parameters over a period

\begin{tabular}{lll}
\hline Parameter & Deviation from the mean & Unit \\
\hline Total solar insolation, $G_{T}$ & \pm 50 & $\mathrm{~W} / \mathrm{m}^{2}$ \\
Ambient temperature, $T_{a}$ & \pm 1 & $\mathrm{~K}$ \\
Wind speed, $V_{w}$ & $2-4$ & $\mathrm{~m} / \mathrm{s}$ \\
Fluid mass flow rate, $\dot{m}$ & \pm 1 & $\%$ \\
Collector fluid inlet temperature, $T_{i}$ & \pm 0.1 & $\mathrm{~K}$ \\
\hline
\end{tabular}

\section{Efficiency of ETSC}

The useful energy was determined using Eq. (4), with measured values for the inlet and outlet fluid temperatures and fluid mass flow rate. The specific heat capacity was determined using Eq. (3). The useful energy can also be expressed in terms of the energy absorbed by the collector and the energy lost to the surroundings as given by Eq. (5) (Duffie \& Beckman, 2006).

$$
Q_{u}=\dot{m} C_{p}\left(T_{o}-T_{i}\right)
$$

and

$$
Q_{u}=\dot{m} \frac{C_{p}\left(T_{o}-T_{i}\right)}{A \cdot G_{T}}
$$

\section{RESULTS AND DISCUSSION}

The solar insolation, $\mathrm{G}_{\mathrm{T}}$, is an important parameter to evaluate the efficiency of the collector. It is dependent on the geographic location, weather and climate. In the present 
experiment, weather conditions such as passing clouds, cloudy sky, rain, etc. influence the solar insolation values. Figure 4 shows the typical solar insolation against time on a clear sky and cloudy day respectively. It was observed that for a clear sky day the variation in solar insolation was parabolic, with the maximum reached at about 2.00 p.m. The maximum insolation on the tilted surface of the ETSC was about 958 $\mathrm{W} / \mathrm{m}^{2}$ on that particular day. Nevertheless, on a cloudy day the solar insolation exhibited an irregular pattern, and the solar insolation would rise and drop throughout the day according to the clouds. The maximum recorded insolation on this day was $630 \mathrm{~W} / \mathrm{m}^{2}$. Therefore the steady or quasi-steady state condition was difficult to achieve under such weather conditions, and testing was only conducted on a clear sky day.

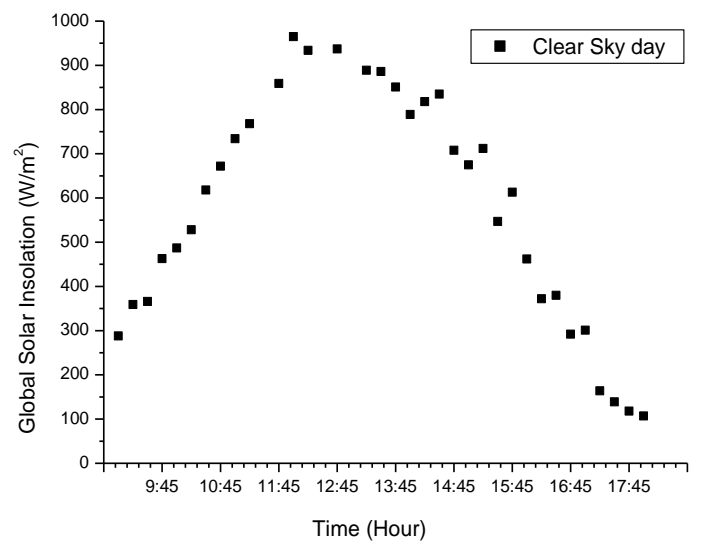

(a) Clear sky day

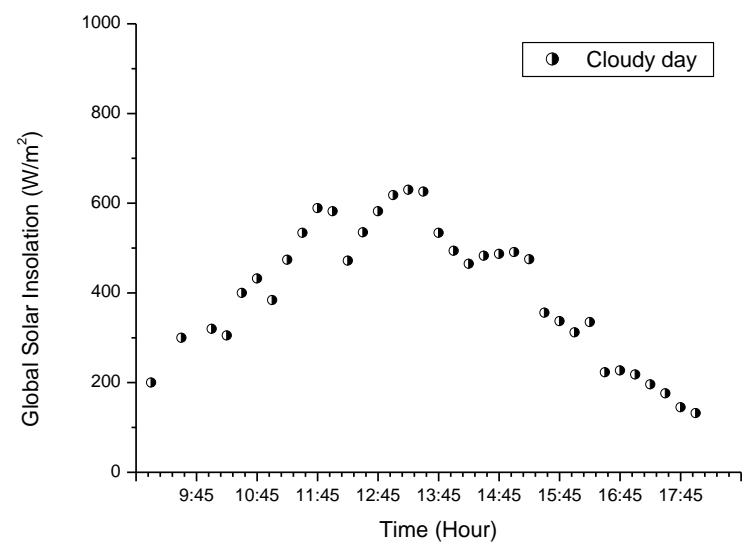

(b) Cloudy day

Figure 4. Solar insolation against time.

Experimental data on the clear sky day were tabulated according to the solar insolation incident at the site. The temperatures at the inlet and outlet of the setup are recorded for the water and nanofluid. The temperature difference between the inlet and outlet is then estimated. An average value for the insolation is considered in the analysis after a repeated number of tests. The data for the water and nanofluid are shown plotted in Figure 6.

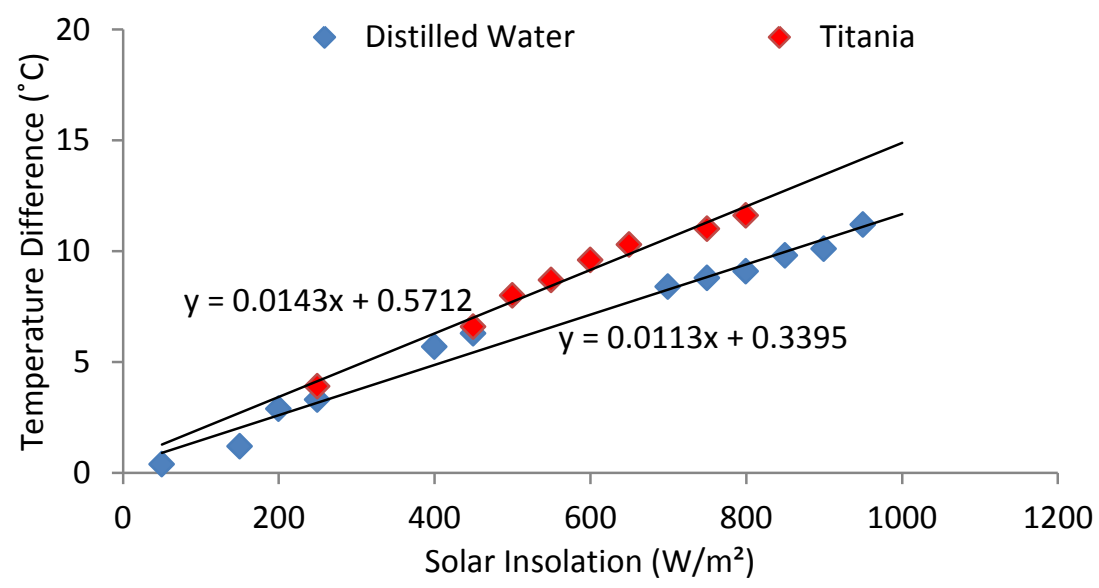

Figure 6. Average temperature difference of water and $0.3 \%$ Titanium Oxide $\left(\mathrm{TiO}_{2}\right)$ against solar insolation $\left(\mathrm{W} / \mathrm{m}^{2}\right)$. 
Based on Figure 6, the nanofluid and water temperature differences are directly proportional to the solar insolation. $\mathrm{TiO}_{2}$ nanofluid has a higher temperature difference than water. The presence of $\mathrm{TiO}_{2}$ nanoparticles enhances the thermal properties compared to water. These enhancements increase the capability to transfer heat from the absorber plate to the working fluid. The heat transfer capability of the nanofluid increases with solar insolation availability. It means that the nanofluids have the ability to absorb heat at higher solar insolation levels and perform better at higher temperatures compared to water. From Figure 6 statistical analysis is performed on the water and nanofluid. The equations from the statistical analysis are used to estimate the temperature difference for other ranges of solar insolation. The temperature difference of the nanofluid increased by a maximum of $19.0 \%$ compared to water.

The instantaneous efficiency was determined using Eq. (5) for the experimental data, as shown in Figure 7. The mass flow rate of the system was kept constant throughout the experiment for the water and $\mathrm{TiO}_{2}$ nanofluid. The specific heat capacity of the $\mathrm{TiO}_{2}$ nanofluid was determined using Eq. (3). The aperture area of the collector was the absorber area for solar energy. From Figure 7, the efficiency of the $\mathrm{TiO}_{2}$ nanofluid is higher than water, where the maximum efficiencies are 0.73 and 0.58 respectively. The efficiency of the system using $0.3 \% \mathrm{TiO}_{2}$ nanofluid has increased by $16.67 \%$ compared to water. The system using the water-based $\mathrm{Al}_{2} \mathrm{O}_{3}$ nanofluid is predicted to have an $8 \%$ higher efficiency compared to the water-based $\mathrm{TiO}_{2}$ nanofluid because of its higher thermal conductivity.

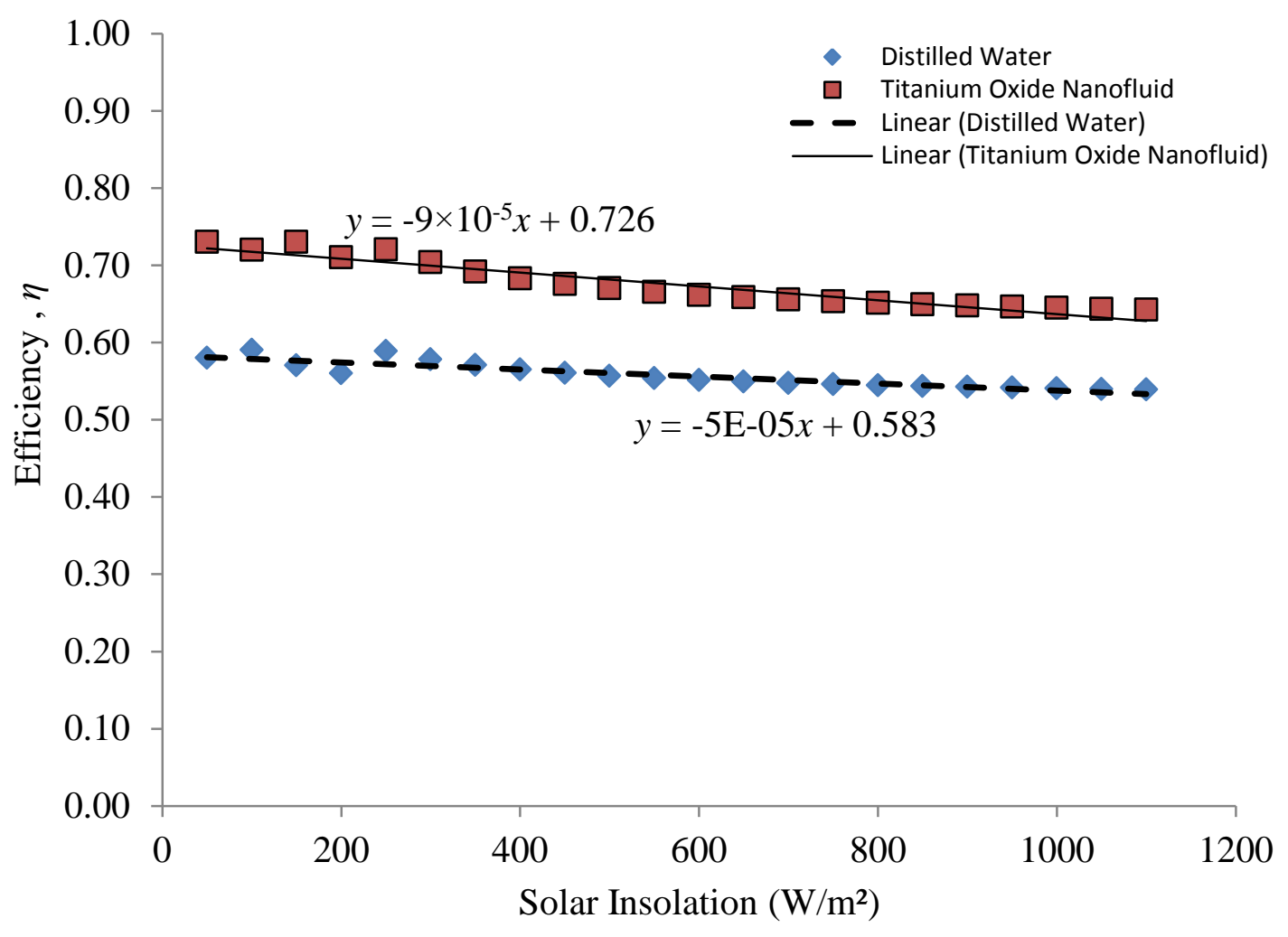

Figure 7. Efficiency of water and $0.3 \%$ Titanium Oxide $\left(\mathrm{TiO}_{2}\right)$ against solar insolation $\left(\mathrm{W} / \mathrm{m}^{2}\right)$ 


\section{CONCLUSIONS}

The temperature rise in the nanofluid is $19.0 \%$ higher than water at the exit of the collector. The maximum efficiency of the system using $0.3 \% \mathrm{TiO}_{2}$ nanofluid is 0.73 , and for distilled water it is 0.53 . The efficiency of the system has increased by $16.67 \%$ compared to its base liquid. The greater the solar insolation, the higher the temperature difference achieved for the $\mathrm{TiO}_{2}$ nanofluid. The ETSC system using a water-based $\mathrm{Al}_{2} \mathrm{O}_{3}$ nanofluid is predicted to have an $8 \%$ higher efficiency compared to the waterbased $\mathrm{TiO}_{2}$ nanofluid.

\section{ACKNOWLEDGMENT}

The research was financially supported by the University Malaysia Pahang with grant number RDU110327.

\section{REFERENCES}

Badar, A. W., Buchholz, R., \& Ziegler, F. (2011). Experimental and theoretical evaluation of the overall heat loss coefficient of vacuum tubes of a solar collector. Solar Energy, 85 (7), 1447-1456.

Choi, S. U. S., \& Eastman, J. A. (1995). Enhancing thermal conductivity of fluids with nanoparticles. International mechanical engineering congress and exhibition, San Francisco, CA, USA, pp.1-8.

Das, S. K., Choi, S. U. S., Yu, W., \& Pradeep, T. (2007). Nanofluids: science and technology. New York, Wiley-Interscience.

Duffie, J. A., \& Beckman, W. A. (2006). Solar engineering of thermal processes. New York: Wiley-Interscience.

Gordon, J., \& Society, I. S. E. (2001). Solar energy the state of the art. United Kingdom: International Solar Energy Society.

Hwang, Y. J., Ahn, Y. C., Shin, H. S., Lee, C .G., Kim, G. T., Park, H. S., \& Lee, J. K. (2006). Investigation on characteristics of thermal conductivity enhancement of nanofluids. Current Applied Physics, 6 (6), 1068-1071.

Lee, S., Choi, S. U. S., Li, S., \& Eastman, J. A. (1999). Measuring thermal conductivity of fluids containing oxide nanoparticles. Journal of Heat Transfer, 121 (2), 280289.

Morrison, G. L., Budihardjo, I., \& Behnia, M. (2005). Measurement and simulation of flow rate in a water-in-glass evacuated tube solar water heater. Solar Energy, 78 (2), 257-267.

Natarajan, E., \& Sathish R. (2009). Role of nanofluids in solar water heater. International Journal of Advanced Manufacturing Technology, 1-5.

Nayak, S. P. S. J. K. (2008). Solar energy: principles of thermal collection and storage. Tata, Singapore, McGraw-Hill.

Otanicar, T. P., Phelan, P. E., Prasher, R. S., Rosengarten, G., \& Taylor, R. A. (2010). Nanofluid-based direct absorption solar collector. Journal of Renewable and Sustainable Energy, 2 (3), 033102-033113.

Othman, M. Y. H., Sopian, K., Yatim, B., \& Dalimin, M. N. (1993). Diurnal pattern of global solar radiation in the tropics: a case study in Malaysia. Renewable Energy, 3(6-7), 741-745. 
Pak, B. C., \& Cho, Y. I. (1998). Hydrodynamic and heat transfer study of dispersed fluids with submicron metallic oxide particles. Experimental Heat Transfer, 11 (2), 151-170.

Srinivasa Rao, G., Sharma, K. V., Chary, S. P., Bakar, R. A., Rahman, M. M., Kadirgama, K., \& Noor, M. M. (2011). Experimental study on heat transfer coefficient and friction factor of $\mathrm{Al}_{2} \mathrm{O}_{3}$ nanofluid in a packed bed column. Journal of Mechanical Engineering and Sciences, 1, 1-15.

Syam Sundar, L., \& Sharma, K. V. (2011a). An experimental study heat transfer and friction factor of $\mathrm{Al}_{2} \mathrm{O}_{3}$ nanofluid. Journal of Mechanical Engineering and Sciences, 1, 99-112.

Syam Sundar, L., \& Sharma, K.V. (2011b). Laminar convective heat transfer and friction factor of $\mathrm{Al} 2 \mathrm{O} 3$ nanofluid in circular tube fitted with twisted tape inserts. International Journal of Automotive and Mechanical Engineering, 3, 265-278.

Yousefi, T., Veysi, F., Shojaeizadeh, E., \& Zinadini, S. (2012). An experimental investigation on the effect of $\mathrm{Al}_{2} \mathrm{O}_{3}-\mathrm{H}_{2} \mathrm{O}$ nanofluid on the efficiency of flat-plate solar collectors. Renewable Energy, 39 (1), 293-298.

Zhou, L. P., Wang, B. X., Peng, X. F., Du, X. Z., \& Yang, Y. P. (2010). On the specific heat capacity of $\mathrm{CuO}$ nanofluid. Advances in Mechanical Engineering, 1-4.

Zhu, H. T., Lin, Y. S., \& Yin, Y. S. (2004). A novel one-step chemical method for preparation of copper nanofluids. Journal of Colloid and Interface Science, 277 (1), 100-103. 